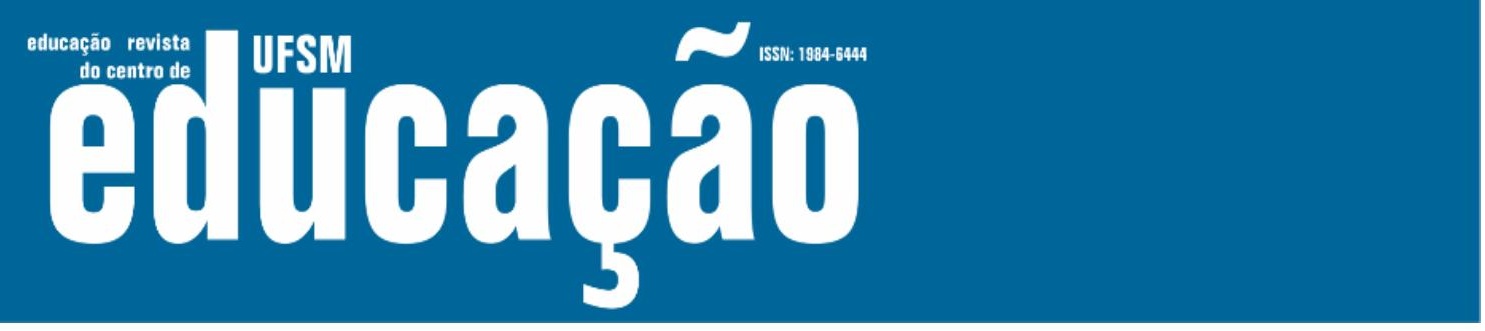

ISSN: 1984-6444 | http://dx.doi.org/10.5902/1984644462013

\title{
Juventude e educação: a militarização das escolas em Goiás
}

\section{Youth and education: the militarization of schools in Goiás}

\author{
Flávio Munhoz Sofiati \\ Professor Associado da Universidade Federal de Goiás. Goiânia, Goiás, Brasil. \\ flavio_sofiati@gmail.com - http://orcid.org/0000-0002-6422-4471 \\ Caio Henrique Salgado Barbosa \\ Universidade Federal de Goiás. Goiânia, Goiás, Brasil. \\ caiohenrique.salgadobarbosa@gmail.com - http://orcid.org/0000-0002-6630-1741
}

Recebido em 30 de outubro de 2020

Aprovado em 04 de dezembro de 2020

Publicado em 04 de setembro de 2021

\section{RESUMO}

O artigo analisa as consequências do processo de implementação dos Colégios da Polícia Militar do Estado de Goiás, Brasil, a partir dos conceitos de controle do corpo e de instituições totais, mostrando como esse modelo autoritário está intimamente ligado à política de restrição da liberdade de expressão da comunidade escolar. $\mathrm{O}$ texto analisa os argumentos dos agentes públicos para a vertiginosa expansão desse modelo educacional e faz uma leitura crítica das regras de conduta aplicadas às unidades educacionais militarizadas no Estado. Constata-se que as normas aplicadas à comunidade escolar nestas unidades - como, por exemplo, a presença cotidiana de uma sequência de atividades garantidas por mecanismos de punição estabelecidos por uma hierarquia e o conjunto de regras que padronizam o visual dos estudantes e causam a perda de identidade - permitem controle rígido das ações de docentes e discentes, regrada a partir da tutela de oficiais designados pelo comando-geral da Polícia Militar, limitando inclusive a liberdade de expressão, considerado como preceito fundamental para uma educação cidadã.

Palavras-chave: Juventude; Educação; Colégios Militares.

\section{ABSTRACT}

The article analyses the consequences of the implementation process of the Colleges of the Military Police of the State of Goiás, Brazil, based on the concepts of body control and total institutions, showing how this authoritarian model is closely linked to the policy of restricting the freedom of expression of the school community. The text analyzes the arguments of public agents for the vertiginous expansion of this educational model 




ISSN: 1984-6444 | http://dx.doi.org/10.5902/1984644462013

Continuação da Tabela 1 - Quantidade de Colégios Estaduais da Polícia Militar por município do Estado de Goiás, em 2020

\begin{tabular}{|l|c|}
\hline \multicolumn{1}{|c|}{ Município } & Quantidade \\
\hline Pires do Rio & 1 \\
\hline Porangatu & 1 \\
\hline Posse & 1 \\
\hline Quirinópolis & 1 \\
\hline Rio Verde & 1 \\
\hline Rubiataba & 1 \\
\hline Sanclerlândia & 1 \\
\hline São Luiz dos Montes Belos & 1 \\
\hline Senador Canedo & 1 \\
\hline Uruaçu & 1 \\
\hline Valparaiso & 1 \\
\hline Total & $\mathbf{6 0}$ \\
\hline
\end{tabular}

Fonte: Portal CEPMG (2020).

Tabela 2 - Quantidade de Colégios Estaduais da Polícia Militar de Goiás por município da Região Metropolitana de Goiânia, em 2020.

\begin{tabular}{|l|c|}
\hline \multicolumn{1}{|c|}{ Município } & Quantidade \\
\hline Goiânia & 8 \\
\hline Aparecida de Goiânia & 3 \\
\hline Trindade & 3 \\
\hline Goianira & 2 \\
\hline Goianápolis & 1 \\
\hline Guapó & 1 \\
\hline Hidrolâncida & 1 \\
\hline Inhumas & 1 \\
\hline Nerópolis & 1 \\
\hline Senador Canedo & 1 \\
\hline Total & $\mathbf{2 2}$ \\
\hline
\end{tabular}

Fonte: Portal CEPMG (2020).

A expansão do modelo militarizado a partir de 2015 consolidou a posição de Goiás como o Estado com o maior número de colégios administrados pela PM. Uma reportagem da Revista IstoÉ, sobre o modelo de escolas cívico-militares que está 


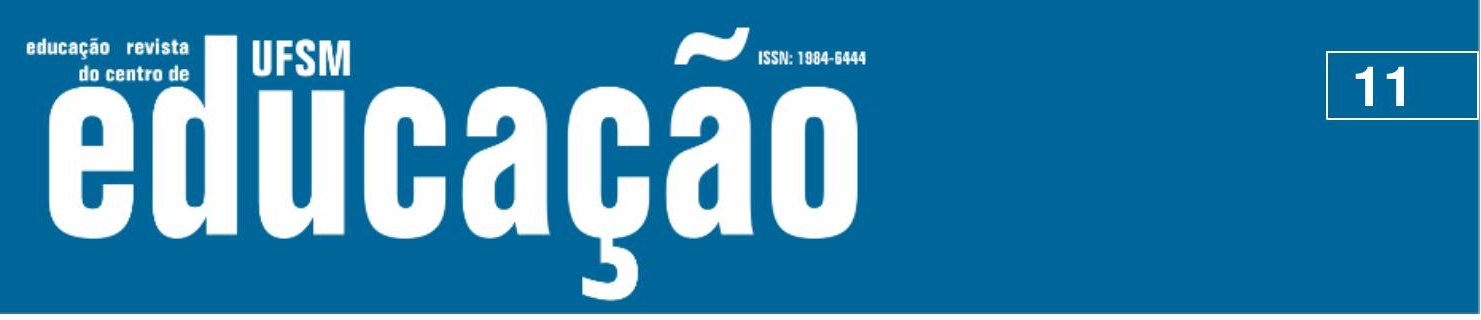

ISSN: 1984-6444 | http://dx.doi.org/10.5902/1984644462013

ocasião de entrada ou saída"; "sentar-se no chão estando uniformizado"; "Dirigir memoriais ou petições a qualquer autoridade, sobre assuntos da alçada do comandante do CEPMG" (CEPMG, 2017, p. 47-48).

Por último, seguem exemplos de transgressões graves: "promover ou tomar parte de qualquer manifestação coletiva e/ou espalhar boatos ou notícias que venham a macular o nome do CEPMG ou a comunidade escolar"; "provocar ou tomar parte em manifestações de natureza política, em horário pedagógico"; "manter contato físico que denote envolvimento de cunho amoroso (namoro, abraços, beijos, etc.) dentro do Colégio, em suas adjacências ou em ato representativo escolar ou fora dele, estando uniformizado;"; "pichar ou causar qualquer poluição visual ou sonora dentro e nas proximidades do CEPMG"; "Desrespeitar os Símbolos Nacionais” (CEPMG, 2017, p. 49).

Fica evidente na análise do regimento interno dos colégios militares que há uma preocupação com o controle do posicionamento político e ideológico dos alunos, assim como de toda a comunidade escolar, especialmente quando se trata de ações coletivas. Faz-se necessário considerar, também, que a ampliação da política de instituição de escolas militarizadas coincide com o aumento das práticas coletivas de jovens que desde 2013 reassumiram um papel político importante na cena política brasileira, principalmente com as ocupações de universidade e escolas em todo o país (GROPPO, 2018; BECK, 2019).

O controle também fica evidente quando o documento define padrões de comportamento para os docentes. Mesmo não sendo vigiados por um profissional militar designado especificamente para isto, assim como acontece com os estudantes, os professores dos colégios militares goianos também atuam sob regras rígidas, estabelecidas através dos "deveres e vedações" impostos à comunidade escolar em geral.

É dever de todos, por exemplo, "comunicar à direção, imediatamente, todas as irregularidades que tenha conhecimento". Entre as vedações estão "fazer proselitismo religioso, político-partidário ou ideológico, em qualquer circunstância, bem como, pregar doutrinas contrárias aos interesses nacionais, influenciando os demais membros da comunidade à tomada de atitude indisciplinada, irreverente ou de 




ISSN: 1984-6444 | http://dx.doi.org/10.5902/1984644462013

1999, p. $6-8)$.

Após descrever com detalhes que chocam a morte de Damiens, Foucault aponta que, na transição entre os séculos XVIII e XIX, estas punições públicas e violentas passaram a dar lugar à coerção dos indivíduos com treinamento dos corpos via imposição de disciplinas rígidas. A violência e a coerção ganham um caráter simbólico que remete a Pierre Bourdieu (1989, p. 14), quando o mesmo aponta que os "sistemas simbólicos" cumprem sua função de imposição e legitimação da dominação. Este método está presente nas prisões modernas, onde há hora, local e padrões de comportamento definidos para cada ação dos presos, mas não só. Segundo Foucault:

\footnotetext{
O momento histórico das disciplinas é o momento em que nasce uma arte do corpo humano, que visa não unicamente o aumento de suas habilidades, nem tampouco aprofundar sua sujeição, mas a formação de uma relação que no mesmo mecanismo o torna tanto mais obediente quanto é mais útil, e inversamente. Forma-se então uma política das coerções que são um trabalho sobre o corpo, uma manipulação calculada de seus elementos, de seus gestos, de seus comportamentos (FOUCAULT, 1999, p.163).
}

O autor entende que: "A "invenção" dessa nova anatomia política não deve ser entendida como uma descoberta súbita. Mas como uma multiplicidade de processos muitas vezes mínimos" (FOUCAULT, 1999, p.163). E constata: "Encontramo-los em funcionamento nos colégios, muito cedo; mais tarde nas escolas primárias; investiram lentamente o espaço hospitalar; e em algumas dezenas de anos reestruturam a organização militar" (FOUCAULT, 1999, p.163).

Esta imposição da disciplina tem como função primordial o "adestramento" que visa fabricar seres obedientes de forma discreta e sem os excessos dos suplícios. Surge "um poder modesto, desconfiado, que funciona a modo de uma economia calculada, mas permanente" e de "procedimentos menores se os compararmos aos rituais majestosos da soberania ou aos grandes aparelhos do Estado". O poder disciplinar se impõe a partir do "olhar hierárquico, a sanção normalizadora e sua combinação num procedimento que lhe é específico, o exame" (FOUCAULT, 1999, p. 191).

O autor entende que: 


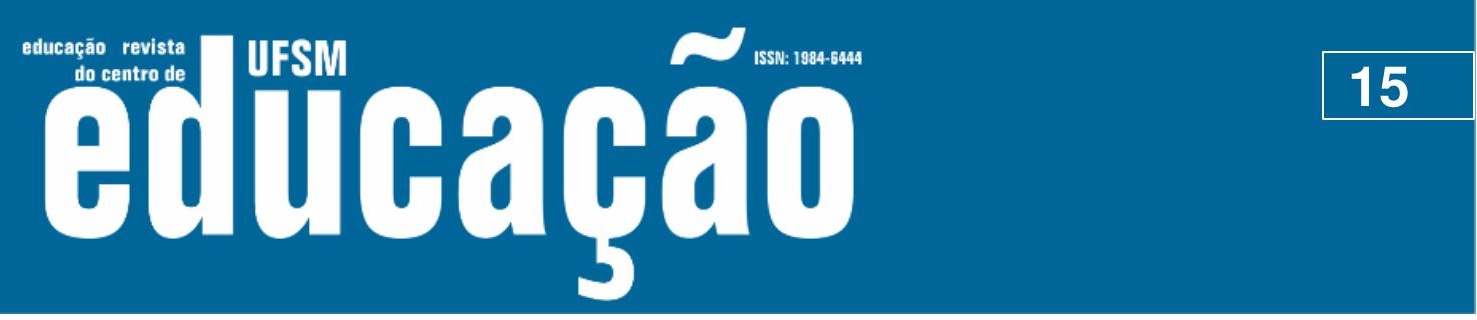

ISSN: 1984-6444 | http://dx.doi.org/10.5902/1984644462013

A disciplina é uma técnica de poder que implica uma vigilância perpétua e constante dos indivíduos. Não basta olhá-los às vezes ou ver se o que fizeram é conforme a regra. É preciso vigiá-los durante todo o tempo da atividade de submetê-los a uma perpétua pirâmide de olhares. É assim que no exército aparecem sistemas de graus que vão, sem interrupção, do general chefe até o ínfimo soldado, como também os sistemas de inspeção, revistas, paradas, desfiles, etc., que permitem que cada indivíduo seja observado permanentemente (FOUCAULT, 2014 p. 106).

Foucault (1999, p. 166) detalha como os ambientes escolares reproduzem esta lógica de disciplina constante que é comum em quartéis, procedendo, primeiramente, a partir da distribuição dos indivíduos no espaço. Em seguida, vem o "quadriculamento", ou seja: "cada indivíduo no seu lugar; e em cada lugar, um indivíduo" (FOUCAULT, 1999, p. 167). Procedimentos complementares aos dois primeiros são identificados nas localizações funcionais, permitindo que os passos de cada indivíduo sejam controlados de forma minuciosa (FOUCAULT, 1999, p. 168).

Os estudos de Foucault dão conta basicamente do modelo dos internatos que foram se consolidando, especialmente a partir do século XIX, inspirados nos conventos. Mas padrões semelhantes podem ser observados, em maior ou menor grau, nas instituições de ensino contemporâneas, como mostra Inês Araújo:

\begin{abstract}
A fila, a carteira, o treino para a escrita, os exercícios com dificuldades crescentes, a repetição, a presença num tempo e num espaço recortados, a punição pelo menor desvio de conduta, a vigilância por parte de um mestre ou monitor, as provas, os exames, os testes de aprendizagem e de recuperação, o treinamento dentro de padrões e normas fixos. $E$ mais, os resultados dos esforços pedagógicos sendo permanentemente avaliados por critérios também eles padronizados, leva a uma simples análise de boletins, que sirva para medir os casos que desviam, portanto, serve para marcar, excluir, normalizar (ARAÚJO, 2002, p. 79).
\end{abstract}

Se para Araújo o controle dos corpos é regra nas instituições escolares atuais, no caso das escolas e colégios militarizados em Goiás estas práticas parecem se manifestar de forma mais intensa e explicita, uma vez que cada detalhe, inclusive a aparência dos alunos, é regulado com precisão. A escola militarizada aparece como um antídoto ao movimento global de ação coletiva das novas gerações, nos moldes abordados por Dayrell e Oliveira (2018), que demonstram o papel político das juventudes nas manifestações contemporâneas antissistema. 


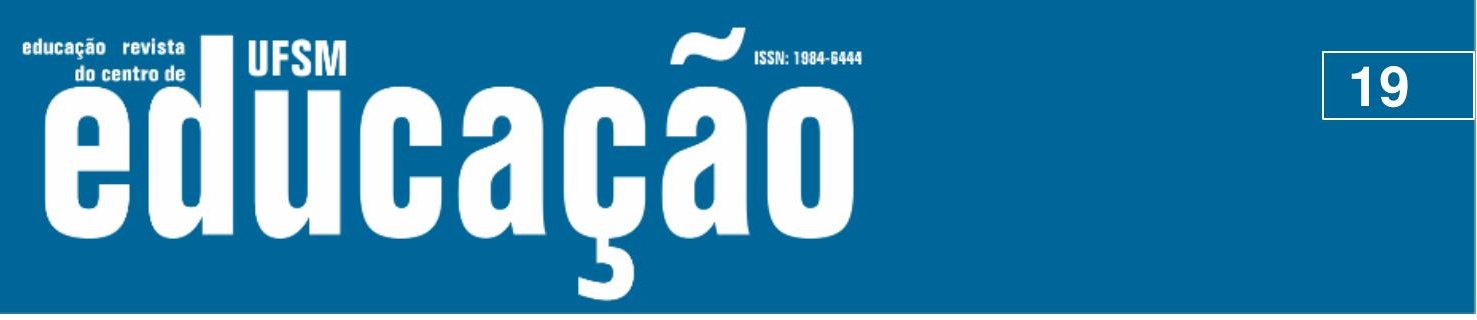

ISSN: 1984-6444 | http://dx.doi.org/10.5902/1984644462013

Art. 211. A continência individual que trata o artigo anterior deverá ser feita da seguinte maneira:

I - aluno parado e superior deslocando:

a) posição de sentido, frente para o superior, leva a mão ao lado direito da fronte; a mão no prolongamento do antebraço, com a palma voltada para o rosto e com os dedos unidos e distendidos; o braço sensivelmente horizontal, formando um ângulo de $45^{\circ}$ graus com a linha dos ombros; olhar franco e naturalmente voltado para o superior. Para desfazer a continência, baixa a mão em movimento enérgico, voltando à posição de sentido.

b) A continência é feita quando o superior atinge a distância de três passos e desfeita um passo depois que o mesmo ultrapassar o aluno.

II - aluno deslocando-se e superior parado ou deslocando-se em sentido contrário:

a) se estiver deslocando em passo normal, o aluno fará a continência a três passos do superior, encarando-o com o olhar franco, desfazendo a continência um passo depois.

III - aluno, deslocando-se alcança e ultrapassa o superior que se desloca no mesmo sentido:

a) o aluno ao alcançar o superior, faz a continência.

IV - aluno, deslocando-se é alcançado e ultrapassado pelo superior que se desloca no mesmo sentido:

a) ao ser alcançado, o aluno faz a continência e a desfaz quando o superior tiver afastado um passo (CEPMG, 2017, p. 57).

O mesmo nível de detalhamento é utilizado no Regimento Interno para definir o uso dos uniformes e a padronização visual. Aos homens é proibido o uso de costeletas e é definido um corte de cabelo padrão, denominado "meia cabeleira", "em

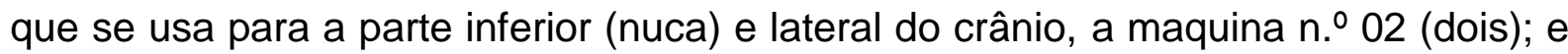
para a parte superior do crânio a maquina n. 04 (quatro)". No caso das alunas, são previstos cortes curtos, médios e longos. Caso seja adotada uma das duas últimas opções, "os cabelos deverão ser presos por 'coque', 'rabo-de-cavalo', ou 'rabo de cavalo trançado de forma simples', quando a aluna estiver com o $3^{\circ}$ uniforme (básico) e $6^{\circ}$ uniforme (bata para gestantes)'” (CEPMG, 2017, p. 61 - p. 66).

É evidente a relação com uma das características das instituições totais. Segundo Goffman (2015, p. 28), é "muito provável que o indivíduo seja despido de sua aparência usual, bem como dos equipamentos e serviços com os quais mantém, o que provoca desfiguração pessoal". A referência a itens de higiene se deve ao fato de o autor considerar o isolamento do mundo externo, aos moldes de um internato, como característica fundamental das instituições totais. Apesar de estes exemplos não se encaixarem no nosso tema de estudo, é importante mencionar que a regulamentação dos colégios militares goianos exclui "lentes ou armações de cores 


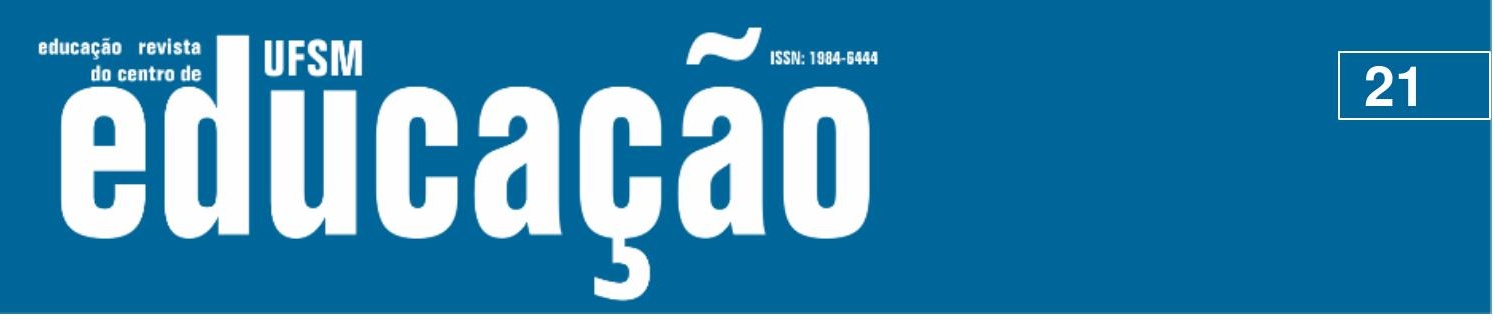

ISSN: 1984-6444 | http://dx.doi.org/10.5902/1984644462013

\section{Considerações finais}

A leitura critica do discurso utilizado para a expansão sem precedentes do modelo de ensino militarizado e das regras que ditam o funcionamento das unidades educacionais militarizadas em Goiás a partir da obra de Michel Foucault e de Erving Goffman revela que este projeto do Governo de Goiás, de forte caráter disciplinador, traz consigo uma ideia de docilização dos corpos. Trata-se de uma proposta de ensino que define padrões rígidos de comportamento; ela classifica e pretende evitar possíveis atitudes de professores e alunos que são vedadas e/ou tidas como transgressoras.

Além de tratarem das mais variadas posturas corporais e comportamentais, as regras estabelecidas para o ensino militarizado goiano indicam especial preocupação com posicionamentos político-partidários e buscam reprimir qualquer tipo de questionamento das autoridades instituídas dentro das próprias instituições educacionais e também no governo do Estado, limitando inclusive a liberdade de expressão da comunidade escolar.

Estas normas rígidas também remetem ao conceito de instituições totais de Goffman. Apesar de não atender a todas as características descritas pelo autor, que incluem a alienação total do indivíduo com o mundo fora dos limites físicos da instituição, é notável a existência de semelhanças significativas. Chama a atenção, neste sentido, o controle rígido de uma sequência de atividades e o conjunto de regras que padronizam o visual dos estudantes que causam a perda de identidade. Também são semelhantes as mecânicas que ampliam as possibilidades de punição ou represálias a partir da definição de hierarquia inclusive entre alunos.

Por fim, é fundamental entendermos que a política pública de intervenção militar nos colégios está em perfeita conformidade com a política de governo estabelecida em Goiás nas últimas décadas e levada a diante no atual governo brasileiro. Os padrões determinados para esta política de militarização denotam uma convergência com os pressupostos neoliberais, segundo o qual, é próprio deste modelo a convivência harmônica entre preceitos fundantes da ideia de um Estado 


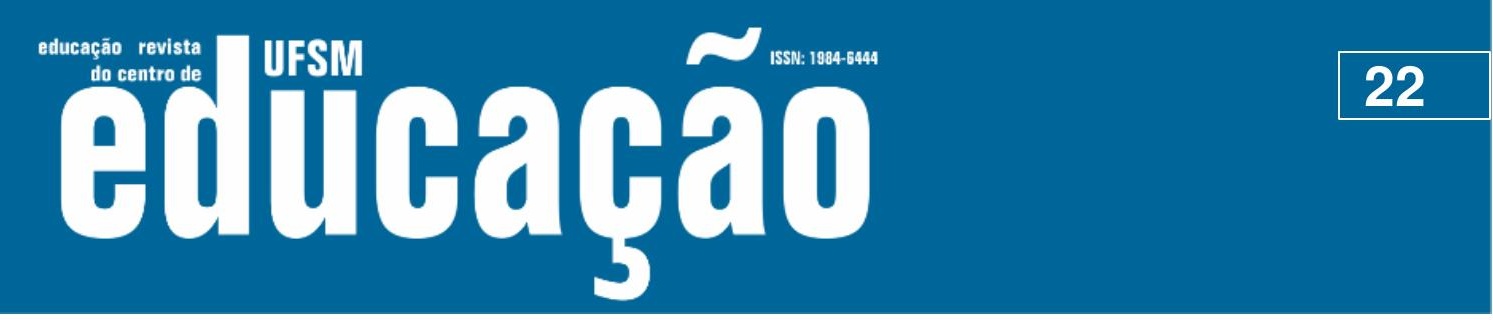

ISSN: 1984-6444 | http://dx.doi.org/10.5902/1984644462013

mínimo na economia e na prestação de serviços, mas que é máximo no controle social, na imposição da disciplina e no encarceramento em massa.

Entende-se que este braço controlador e punitivo recai especialmente sobre populações pobres que são mantidas à margem da sociedade. Não por acaso, este invasivo e autoritário Leviatã funciona como uma espécie de medicamento para a doença crônica cujos sintomas são, entre outros, insegurança e desigualdade sociais.

\section{Referências}

ALVES, Míriam Fábia; TOSCHI, Mirza Seabra; FERREIRA, Neusa Sousa R. A expansão dos colégios militares em Goiás e a diferenciação na rede estadual. In Revista Retratos da Escola, Brasília, v. 12, n. 23, , jul/out., p. 271-287, 2018.

ALVES, Miriam Fábia; REIS, Lívia Cristina Ribeiro ; SANTOS, Eduardo Junior Ferreira; SILVA, Frederiko Luz; FERREIRA, Neusa Sousa Rêgo. Militarização de escolas públicas e o Governo Bolsonaro. In Revista de educação, ciência e tecnologia do IFG, v. 4, p. 227-235, 2019.

ALVES, Miriam Fábia; TOSCHI, Mirza Seabra. A militarização das escolas públicas: uma análise a partir das pesquisas da área de educação no Brasil. In Revista Brasileira de Política e Administração da Educação, v. 35, p. 633-650, 2019.

ARAÚJO, Inês L. Da "pedagogização" à educação: acerca de algumas contribuições de Foucault e Habermas para a filosofia da educação. In Revista Diálogo Educacional, Curitiba, v. 3, n. 7, p. 75-88, set./dez., 2002.

A TARDE. Goiás vai terceirizar a educação, após experiência na saúde. Disponível em: $\quad$ http://atarde.uol.com.br/politica/noticias/1727346-goias-vai-terceirizar-aeducacao-apos-experiencia-na-saude. Acesso em: 19 abr. 2019.

BECK, Marcus V. Diário subversivo: dias de embriaguez, utopia e tesão. Goiânia: Prime, 2019.

BOURDIEU, Pierre. O poder simbólico. Rio de Janeiro: Bertrand Brasil, 1989.

CEPMG. Regimento Escolar. Goiânia, 2017.

CARRANO, Paulo C. R. A escola pública diante do desafio de educar em relações de liberdade e convivência democrática. In Nora Krawczyk. (Org.). Escola pública: tempos difíceis, mas não impossíveis. Campinas: FE/UNICAMP, 2018. 


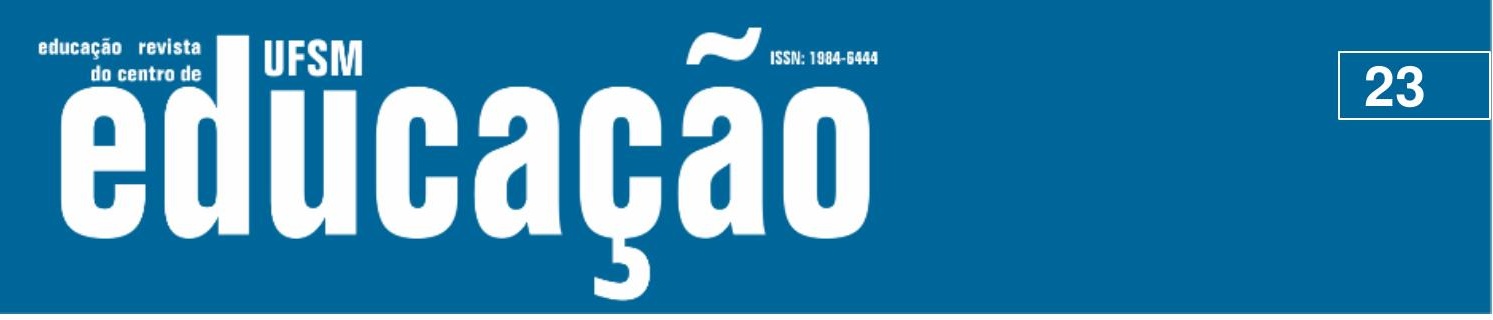

ISSN: 1984-6444 | http://dx.doi.org/10.5902/1984644462013

CRUZ, Leandra Augusta de Carvalho Moura. Militarização das Escolas Públicas em Goiás: Disciplina ou Medo? Dissertação (Dissertação em história) - PUC-GO. Goiânia, 2017.

D' ANTOLA, Arlete (Org.). Disciplina na Escola: Autoridade Versus Autoritarismo. São Paulo: EPU, 1989.

DAYRELL, Juarez; OLIVEIRA, I. T. M. Práticas e imaginários da contestação social global : jovens, coletivos, movimentações e dissensos. In Alexsandra Borges Fernandes; Leide Maria Cota; Vanessa Costa de Macedo. (Org.). Trabalho, renda e diversidade: debates contemporâneos na universidade. 11ed. Belo Horizotne: Mazza Edições, 2018.

FERNANDES, Francisco. Dicionário de sinônimos e antônimos da língua portuguesa. Rio de Janeiro: Editora Globo, 1997.

FERNANDES, Sílvia. Sociologia da juventude - olhares interdisciplinares e intertemáticos. In Contemporânea - Revista de Sociologia da UFSCar, v. 9, n. 2, maio - agosto, pp. 339-350, 2019.

FOLHA DE SÃO PAULO. Cresce no Brasil o número de escolas básicas públicas
geridas http://www1.folha.uol.com.br/educacao/2015/08/1666631-cresce-no-brasil-o-numerode-escolas-basicas-publicas-geridas-pela-pm.shtm. Acesso em: 19 abr. 2019.

FOUCAULT, Michel. Microfísica do poder. São Paulo: Paz \& Terra, 2014.

FOUCAULT, Michel. Vigiar e punir: nascimento da prisão. 20 ed. Petrópolis: Vozes, 1999.

GALVÃO, Izabel; SPOSITO, Marilia P. La "non-participation" à la lumière des impasses de l'offre participative et des mutations de l'action collective. In Izabel Galvão. (Org.). Le pouvoir d'agir des habitants. Paris: L'Harmattan, 2019.

GOFFMAN, Erving. Manicômios, Prisões e Conventos. São Paulo: Perspectiva, 2015.

GOIÁS. Lei n. 8.125, de 18 de junho de 1976. Dispõe sobre a organização básica da Polícia Militar do Estado de Goiás e dá outras providências. Disponível em: http://www.gabinetecivil.go.gov.br/pagina_leis.php?id=7296. Acesso em: 19 abr. 2019.

GOIÁS. Lei n. 14.044, de 21 de dezembro de 2001. Dispões sobre as unidades do Colégio da Polícia Militar do Estado de Goiás (CPMG). Disponível em: http://www.gabinetecivil.goias.gov.br/leis_ordinarias/2001/lei_14044.htm. Acesso em: 19 abr. 2019. 


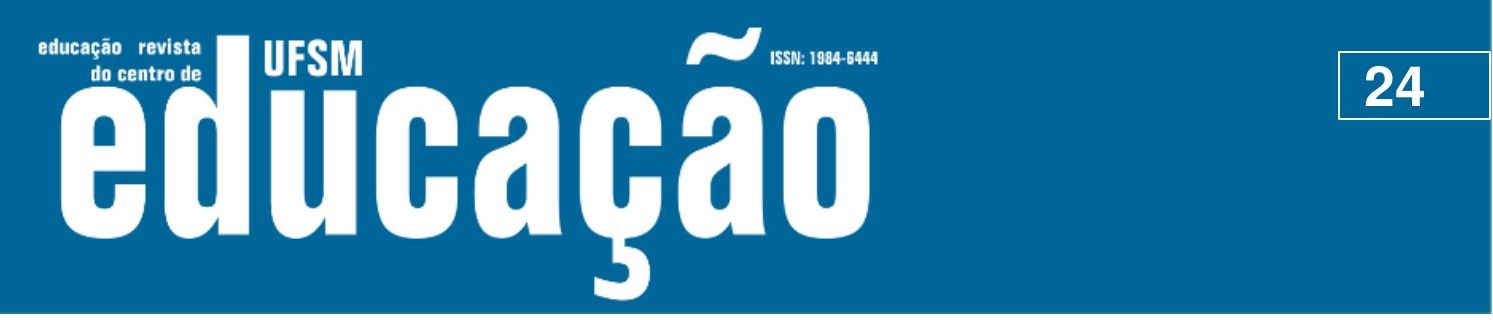

ISSN: 1984-6444 | http://dx.doi.org/10.5902/1984644462013

GOIÁS. Lei n. 18.967, de 22 de julho de 2015. Dispõe sobre a transformação das unidades de ensino que especifica em Colégios Militares e dá outras providências. Disponível em: http://www.gabinetecivil.go.gov.br/pagina_leis.php?id=14192. Acesso em: 19 abr. 2019.

GROPPO, Luís A. O novo ciclo de ações coletivas juvenis no Brasil. In Adriana Alves Fernandes Costa; Luís Antonio Groppo. (Org.). O movimento de ocupações estudantis no Brasil. São Carlos: Pedro\&João, 2018.

GROPPO, Luís A. Juventudes e políticas públicas: comentários sobre as concepções sociológicas de juventude. In DESidades - Revista Eletrônica de Divulgação Científica da Infância e Juventude, v. 5, p. 9, 2017.

ISTOÉ. Colégios públicos com gestão militar chegam a Brasília na era Bolsonaro. Disponível em: https://istoe.com.br/colegios-publicos-com-gestao-militarchegam-a-brasilia-na-era-bolsonaro/. Acesso em: 5 fev. 2020.

OLIVEIRA, S.S.; ALVES, Miriam Fábia. A reforma da gestão das redes estaduais de Goiás e do Rio de Janeiro sob a égide da Nova Gestão Pública. In Política e Gestão Educacional, v. 22, p. 177-192, 2018.

O POPULAR. 12,4\% dos alunos de goiás estudam em colégios militares. Disponível em: https://www.opopular.com.br/noticias/cidades/12-4-dos-alunos-degoi\%c3\%a1s-estudam-em-col\%c3\%a9gios-militares-1.1667183. Acesso em: 20 abr. 2019.

O POPULAR. Sem novas unidades de colégios militares neste ano. Disponível em: $\quad$ https://www.opopular.com.br/noticias/cidades/sem-novas-unidades-decol\%C3\%A9gios-militares-neste-ano-1.1802427. Acesso em: 5 fev. 2020.

PORTAL

CEPMG. Nossas

Unidades.

Disponível

em:

https://www.portalcepmg.com.br/nossas-unidades/. Acesso em: 3 fev. 2020.

PORTAL

CEPMG. Regimento

Interno.

Disponível

em:

https://www.portalcepmg.com.br/regimento-interno/. Acesso em: 15 jan. 2020.

\section{PORTAL MEC. Escolas cívico-militares estarão em 23 estados e no Distrito Federal em 2020. Disponível em: http://portal.mec.gov.br/component/content/article/211-noticias/218175739/82821- escolas-civico-militares-estarao-em-23-estados-e-no-distrito-federal-em- 2020? Itemid=164. Acesso em: 7 fev. 2020.}

SANTOS, Rafael José da Costa. A militarização da escola pública em Goiás. Dissertação (Mestrado em Educação) - Programa de Pós-Graduação Stricto Sensu em Educação, Pontifícia Universidade Católica de Goiás, Goiânia, 2016. 


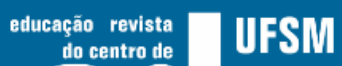 \\ ISSN: 1984-6444

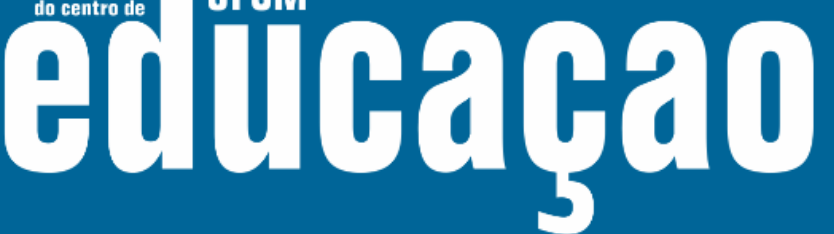

ISSN: 1984-6444 | http://dx.doi.org/10.5902/1984644462013

SPOSITO, Marília P. Celso de Rui Beisiegel: o legado de um intelectual em defesa da educação popular pública. In Educação e Pesquisa, v. 44, p. 1-9, 2018.

\section{(c) $($ ) (2) (8)}

This work is licensed under a Creative Commons Attribution-NonCommercial 4.0 International (CC BY-NC 4.0) 